\title{
Recent problems for the elderly life - diabetes, dementia, frailty
}

Keywords: diabetes, dementia, frailty, locomotive syndrome, Hinohara-ism, New Elderly Association (NEA)

Abbreviations: LCD, low carbohydrate diet; PURE, prospective urban rural epidemiology; AGEs, advanced glycation endproducts; WHO, world health organization; AHA, american heart association; $\mathrm{CVH}$, cardiovascular health; CVD, cardiovascular disease; ASA, american stroke association; NCDs, noncommunicable chronic diseases; RCTs, randomized controlled trials; AHEAD, action for health in diabetes; NEA, new elderly association.

\section{Introduction}

In recent years, three fields have been raised as health problems of elderly people. They are

i) Metabolic syndrome such as diabetes, obesity, hypertension, hyperlipidemia for internal medicine,

ii) Dementia, and/or impaired cognition ability for psychology and psychiatry and

iii)Frailty and locomotive syndrome for orthopaedic and rehabilitation medicine.

These topics would be introduced and discussed in this article.

\section{Comment}

Firstly, diabetes shows decreased insulin secretion from beta cell of pancreas and the presence of insulin resistance. These disorders were expressed as homeostasis model assessment of insulin resistance (HOMA-R) and homeostasis model assessment of $\beta$ cell function (HOMA- $\beta) .{ }^{1}$ From the clinical point of view, there is common pathophysiological mechanism of insulin resistance which is found in diabetes, hypertension, hyperlipidemia, obesity, metabolic syndrome and so on. Consequently, weight reduction and diet therapy would be necessary.

As to clinical practice, there is common path physiological mechanism of hinsulin resistance which is found in diabetes, hypertension, Hyperlipidemia, obesity, metabolic syndrome and so on. Consequently, weight reduction and diet therapy would be necessary. Recent topics include low carbohydrate diet (LCD) compared with previous Calorie Restriction (CR) diet. LCD was initiated by Atkins and Bernstein in 1990' in western countries, ${ }^{2,3}$ followed by various studies such as DIRECT and Prospective Urban Rural Epidemiology (PURE) study. ${ }^{4,5}$ After that, our diabetes research group started LCD in Japan and developed medically and socially through the activity of Japan LCD promotion association. ${ }^{6,7}$ We proposed three types of LCD meal in every day, which are super LCD, standard LCD, petite LCD, with carbohydrate ratio $12 \%, 26 \%, 40 \%$, respectively.

From the basic medicine point of view, diabetic status causes well-known complications including macro- and micro-antipathy. These phenomena are from elevated blood glucose and increased mean amplitude of glycemic excursions (MAGE). As the etiology of diabetic changes, there would be impaired microcirculation. ${ }^{8}$ Furthermore, there are four possible mechanisms influencing the
Volume 5 Issue 5 - 2018

Hiroshi Bando

Tokushima University and Medical Research, Japan

Correspondence: Hiroshi Bando, Tokushima University and Medical Research, Tokushima, Japan, Tel +8I 9031872485 , Email pianomed@bronze.ocn.ne.jp

Received: September 17,2018 | Published: September 21, 2018

biochemical changes, which are:

i) Formation of advanced glycation endproducts (AGEs),

ii) Increased flux of glucose and other sugars through the polyol pathway,

iii) Increased flux through the hexosamine pathway, and

iv) Activation of protein kinase C (PKC) isoforms. ${ }^{9}$

Secondly, dementia has been also crucial problem from biopsycho-social point of view. It is related to the progressive prevalence of diabetes and metabolic syndrome due to elevated insulin resistance..$^{10}$ In clinical practice, the diagnosis of dementia is not so easy, because there are so many borderline cases. Then, it is important to consider the adequate strategy to provide better QOL and ADL with comprehensive and integrated judgments of many axes.

Dementia were estimated to be 47 million worldwide in 2015 , and 75 million by 2030, 131 million by $2050 .{ }^{11}$ The World Health Organization (WHO) presented reports in 2012 and 2015 and showed that dementia and Alzheimer's disease would be a global public health priority. ${ }^{12}$

Dementia usually shows difficulty in remembering recent events as early symptom. As it develops, various symptoms can emerge including confusion, disorientation, mood swings, behavioural changes and difficulties in speaking and swallowing. ${ }^{13}$ Further progressive disability with multiple cognitive deterioration interferes QOL, ADL and social activity. ${ }^{13}$

There has been a useful evaluation way by American Heart Association (AHA) concerning the risk of dementia and cognitive decline in aged people. ${ }^{14}$ It is AHA's Life's Simple 7 metrics, in which 7 kinds of life style can be evaluated easily. Furthermore, ideal cardiovascular health $(\mathrm{CVH})$ would be studied as well as the association with cardiovascular disease (CVD) related morbidity and mortality. ${ }^{15}$ Cohort study was done with 6626 participants aged 65 years or older without cardiovascular diseases or dementia at baseline with the follow up about 17 years. ${ }^{16,17}$

Recommended optimal levels of cardiovascular health 7 metrics for ascertainment of cardiovascular health status are in the following:

i) Nonsmoking: never or quit more than 12 months prior, 
ii) Body mass index $<25$,

iii) Physical activity regular physical activity,

iv) Healthy diet: eating fish twice a week or more and fruits and vegetables at least 3 times a day,

v) Total cholesterol $<200 \mathrm{mg} / \mathrm{dL}$ (untreated),

vi) fasting glucose $<100 \mathrm{mg} / \mathrm{dL}$ (untreated),

vii) blood pressure $<120 / 80 \mathrm{mmHg}$ (untreated). ${ }^{15,17}$ By utilizing 7 metrics, a new strategic direction going forward in cardiovascular health promotion and disease prevention would be provided in the projects of AHA and American Stroke Association (ASA). ${ }^{17,18}$

Generally speaking, My Life Check - Life's Simple 7 of AHA has been evaluated routinely in clinical practice, including obesity, smoking, glucose, lipid profiles and blood pressure. However, physical activity has not been so assessed in usual practice due to rather difficulty of correct evaluation. ${ }^{19}$ Physical inactivity has been one of the crucial public health problem, leading to cardiovascular disease (CVD) and noncommunicable chronic diseases (NCDs). ${ }^{20}$ According to recent study, one third of the population worldwide has less than recommended physical activity guidelines. ${ }^{21}$ One of the reasons would be the difficulty to quantify the degree of various physical activities.

AHA has a strategic goal by the year 2020 to reduce $20 \%$ of deaths from stroke and cardiovascular accident, and to promote $20 \%$ of cardiovascular health of all Americans. ${ }^{22}$ Toward the goal, defining optimal brain health in adults would serve to provide AHA/ASA with a new strategic direction in the future.

Thirdly, frailty and locomotive syndrome are also crucial problems. These statuses can be exacerbated by the presence of diabetes and dementia. ${ }^{23}$ Other factors are also affected by metabolic syndrome, obesity, decreased activity, increased immobility, unstable metabolism, malnutrition, bone problems and older age.

As to the treatment and protection of frailty, nutritional supplementation alone without exercise cannot be useful. An effective method is to strengthen resistance movement of the muscles in the aged. ${ }^{24}$ Randomized controlled trials (RCTs) in elderly people with obesity showed improvement in motor function by combined use of weight reduction, aerobic exercise and resistance exercise..$^{23,25}$

The recommended strategy would be improving lifestyle habits. There was a one-year lifestyle habit program, in which a decrease in femoral muscle mass and bone mass were suppressed in elderly patients with obesity. ${ }^{26}$

Lifestyle Intervention Trial has been performed in the previous studies. Among them, the famous RCT is Action for Health in Diabetes (Look AHEAD) study, which is a survey of weight loss for type 2 diabetes. ${ }^{27}$ In the Intensive Lifestyle Intervention group, body function and walking speed were proved to be higher. ${ }^{28}$

In summary, three topics of diabetes, dementia, and frailty are described. Those are not only medical problem and but also bio psycho social problem. In other words, the correction of lifestyle habits may be necessary. From social point of view, Dr. Shigeaki Hinohara who was active until 105 years old, has advocated lifestyle diseases for a long time ago and enlightened the significance of primary care medicine and patient-oriented medicine. ${ }^{29}$ Furthermore, he established "New Elderly Association (NEA)" on 2000 and developed Hinohara-ism in various aspects. ${ }^{30}$ As a result, Japan has evolved into a country where prominent medical and health circumstances are seen..$^{31}$ I hope this article will be useful to anti-aging medicine and happiness of people.

\section{Acknowledgments}

None.

\section{Conflict of interest}

The author declares that there is no conflict interest.

\section{References}

1) Matthews DR, Hosker JP, Rudenski AS, et al. Homeostasis model assessment: insulin resistance and beta-cell function from fasting plasma glucose and insulin concentrations in man. Diabetologia. 1985;28:412419 .

2) Atkins, Robert. Dr. Atkins' New Carbohydrate Gram Counter. M Evans and Company. 1996; 128p.

3) Bernstein RK. Dr. Bernstein's Diabetes Solution. New York: Little, Brown and company. 1997.

4) Shai I, Schwarzfuchs D, Henkin Y, et al. Dietary Intervention Randomized Controlled Trial (DIRECT) Group. N Engl J Med. 2008;359(3):229-241.

5) Dehghan M, Mente A, Zhang X, et al. Prospective Urban Rural Epidemiology (PURE) study investigators Associations of fats and carbohydrate intake with cardiovascular disease and mortality in 18 countries from five continents (PURE): a prospective cohort study. Lancet. 2017;390(10107):2050-2062.

6) Bando H, Ebe K, Manabe T, et al. Less Carbohydrate Intake Increases Serum Ketone Bodies in Low Carbohydrate diet. Endocrinol Metab. 2018;2(1):9.

7) Ebe K, Bando H, Yamamoto K, et al. Daily carbohydrate intake correlates with HbA1c in low carbohydrate diet (LCD). J Diabetol. 2018;1(1):4-9.

8) Tagulchi T, Brownlee M. The Biochemical Mechanisms of Diabetic Tissue Damage. 3rd ed. Pickup JC, Williams G, eds. New Jersey: Blackwell Publishing; 2003.

9) Williams G, Pickup JC Handbook of Diabetes. 3rd ed. New Jersey: Blackwell Publishing; 2004: 288p.

10) Kloppenborg RP, Berg EVD, Kappelle LJ, et al. Diabetes and other vascular risk factors for dementia: Which factor matters most? A systematic review. European Journal of Pharmacology. 2008;585:97-108.

11) Prince M, Wimo A, Guerchet M, et al. World Alzheimer Report 2015: The global impact of dementia. An analysis of prevalence, incidence, costs and trends. London: Alzheimer's Disease International: 2015.

12) WHO and Alzheimer's Disease International (2012) Dementia: a public health priority. Geneva: World Health Organization: 2012.

13) Winblad B, Amouyel P, Andrieu S, et al. Defeating Alzheimer's disease and other dementias: a priority for European science and society. Lancet Neurol. 2016;15(5):455-532.

14) Thacker EL, Gillett SR, Wadley VG, et al. The American Heart Association Life's Simple 7 and incident cognitive impairment: the Reasons for Geographic and Racial Differences in Stroke (REGARDS) study. J AmHeart Assoc. 2014;3(3).

15) Younus A, Aneni EC, Spatz E S, et al. A Systematic Review of the Prevalence and Outcomes of Ideal Cardiovascular Health in US and NonUS Populations. Mayo Clinic Proceedings. 2016;91(5),649-670.

16) Samieri C, Perier MC, Gaye B, et al. Association of Cardiovascular Health Level in Older Age With Cognitive Decline and Incident Dementia. JAMA. 2018;320(7):657-664. 
17) Gaye B, Canonico M, Perier MC, et al. Ideal cardiovascular health, mortality, and vascular events in elderly subjects: the Three-City Study. $J$ AmColl Cardiol. 2017;69(25):3015-3026.

18) Gorelick PB, Furie KL, Iadecola C, et al. Defining Optimal Brain Health in Adults: A Presidential Advisory From the American Heart Association/ American Stroke Association. Stroke. 2017;48(10):284-303.

19) Lobelo, F, Rohm Young D, Sallis R, et al. Routine Assessment and Promotion of Physical Activity in Healthcare Settings: A Scientific Statement From the American Heart Association. Circulation. 2018;137(18):495-522.

20) Lee IM, Shiroma EJ, Lobelo F, et al. Lancet Physical Activity Series Working Group. Effect of physical inactivity on major non-communicable diseases worldwide: an analysis of burden of disease and life expectancy. Lancet. 2012;380:219-229.

21) Hallal PC, Andersen LB, Bull FC, et al. Lancet Physical Activity Series Working Group. Global physical activity levels: surveillance progress, pitfalls, and prospects. Lancet. 2012;380:247-257.

22) Gorelick PB, Furie KL, Iadecola C, et al. Defining Optimal Brain Health in Adults: A Presidential Advisory From the American Heart Association/ American Stroke Association. Stroke. 2017;48(10):284-303.

23) Starr PKN, McDonald SR, Bales CW. Obesity and physical frailty in older adults: a scoping review of lifestyle intervention trials. $\mathrm{J} \mathrm{Am} \mathrm{Med}$ Dir Assoc. 2014;15(4):240-250.
24) Waters DL, Vawter R, Qualls C, et al. Long-term maintenance of weight loss after lifestyle intervention in frail, obese older adults. J Nutr Health Aging. 2013;17(1):3-7.

25) Batsis JA, Gill LE, Masutani RK, et al. Weight loss interventions in older adults with obesity: a systematic review of randomized controlled trials since 2005. J Am Geriatr Soc. 2017;65:257-68.

26) Armamento-Villareal R, Aguirre L, Napoli N, et al. Changes in thigh muscle volume predict bone mineral density response to lifestyle therapy in frail, obese older adults. Osteoporos Int. 2014;25(2):551-558.

27) Johnston CA, Moreno JP, Foreyt JP. Cardiovascular effects of intensive lifestyle intervention in type 2 diabetes. Curr Atheroscler Rep. 2014;16(12):457.

28) Look AHEAD Research Group. Eight-year weight losses with an intensive lifestyle intervention: the look AHEAD study. Obesity (Silver Spring). 2014;22(1):5-13.

29) Hinohara S. The proposal of new term "life style related disease" as adul disease. J Educational Health Service. 1978;5(3):1.

30) Doba N, Hinohara H, Yanai H, et al. The new elder citizen movement in Japan. In: Faces of Aging, the Lived Experience of the Elderly in Japan. Stanford University Press. 2011:36-59.

31) Bando H, Yoshioka A, Iwashimizu Y, et al. Development of Primary Care, Lifestyle Disease and New Elderly Association (NEA) in Japan Common Philosophy With Hinohara-ism. Prim Health Care. 2017;7:281. 